\title{
Is Causal Attribution of Sexual Deviance the Source of Thinking Errors?
}

\author{
Roland Paulauskas ${ }^{1}$ \\ ${ }^{1}$ Department of Psychology, Siauliai University, Lithuania \\ Correspondence: Roland Paulauskas, Department of Psychology, Siauliai University, Lithuania. E-mail: \\ roland.paulauskas@gmail.com
}

Received: November 7, 2012 Accepted: November 23, 2012 Online Published: March 4, 2013

doi:10.5539/ies.v6n4p20 URL: http://dx.doi.org/10.5539/ies.v6n4p20

\begin{abstract}
Adult and juvenile offenders exhibit a number of cognitive distortions related to sexually offending behaviors. The latter may be attributed to their developmental deficiencies, the result of operant conditioning, psychological self-defense mechanisms and biases, influence of negative environmental factors or criminal subculture.

A group of juvenile sex offenders and non-offenders were administered the Causal Attribution of Sexual Deviance Questionnaire (CASDQ). It was found that both populations interpret sexual deviance as a multi-causal phenomenon; however juvenile sex offenders are more likely to externalize its causes as compared to their pro-social peers. The paper discusses the construct of sexual deviance, different etiological theories of sexually aberrant behaviors and explores the relationship between causal attributions and thinking errors as they relate to sexually offending behaviors. It is hypothesized that misinterpretation of the causality of sexual deviance may be the source of cognitive distortions and serve as an internal reinforcer of sexual violence.
\end{abstract}

Keywords: sexual deviance, etiology, causal attribution, cognitive distortions

\section{Introduction}

The concept of sexual deviance refers to the nature of sexual behavior that is nonconforming with societal norms or expectations, is of maladaptive nature and interferes with the individual's functioning (Laws \& O' Donohue, 1997). Sexually deviant behaviors are characterized by one or more of the following criteria: degree of consent; the nature of the person or object involved in the action; the actual action and body parts that are utilized; and the setting in which the behavior is performed. In clinical literature sexual deviance is often referred to as Paraphilia and manifests itself as a disorder characterized by recurrent, intense sexually arousing fantasies, sexual urges or behaviors involving nonhuman objects, suffering and humiliation of oneself or one's partner, children and other non-consenting persons. These fantasies, urges or behaviors last for a period of at least six months and cause distress or interpersonal difficulties (DSM -IV - TR, 2000).

Sexual deviance encompasses a wide spectrum of sexually aberrant behaviors and ranges from exhibitionism, fetishism, voyeurism, pedophilia, to incest and sadistic rape at the extreme end. It is regarded as a major mental health and criminal justice problem by many researchers, clinicians and law enforcement representatives. Other terms related to sexual deviance include sexually abnormal behavior, sexual perversion, sexual assault, and sexual offending; however, their meanings are not identical and the terms are often used in different contexts.

Due to the secretive, immoral and criminal nature of most sexually deviant behaviors, the actual extent and prevalence of this phenomenon is unknown. Among the most common paraphilic acts committed by sex offenders are child molestation, rape, exhibitionism and voyeurism (Abel et al., 1987).

It is estimated that about $50 \%$ of all sex offenders trace back their sexually deviant behavior to adolescence. Approximately $20 \%$ of all rapes and between $30 \%$ and $50 \%$ of all child molestation acts are committed by juveniles (Abel et al., 1985; Becker at al., 1986; Longo \& Groth, 1983). The mean age of the first sexual assault is 14 years (Longo, 1982). This is consistent with the onset of paraphilic interests (Abel \& Osborn, 1992), and indicates that the most effective prevention and treatment of sexual deviance has to take place at an early age. 
Historically, there have been many attempts to explain the causality of sexual deviance. For theoretical purposes all etiological theories can be divided into the following subtypes: intrapersonal (biological, psychological); interpersonal (victim related, peer related); inter-group (family related, school related); societal and integrated perspectives (Hewstone, 1989; Marshall, Barbaree, 1990) (Figure 1).

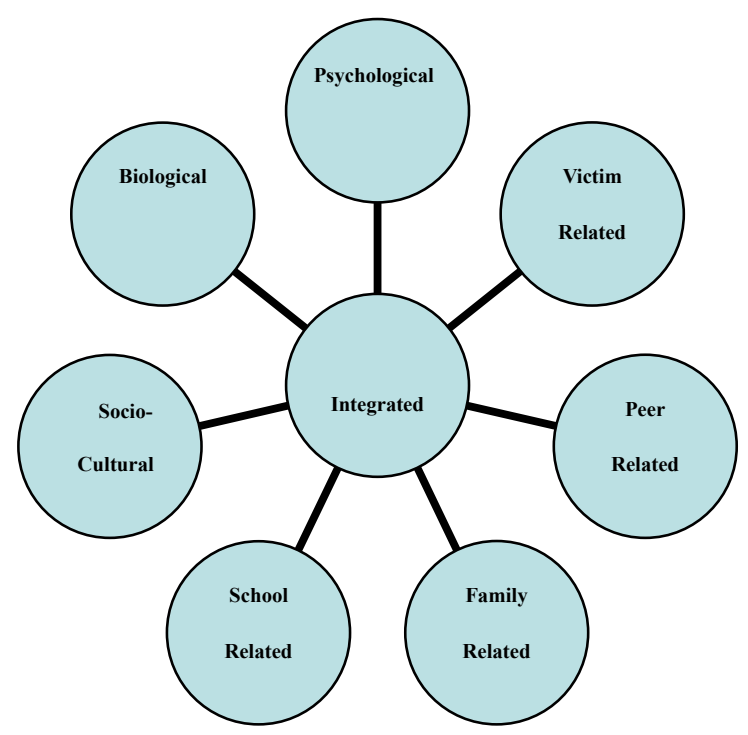

Figure 1. Etiological model of sexual deviance

Intrapersonal theories focus on biological and psychological determinants of sexually aberrant behavior. For example, there is some empirical data supporting the hypothesis that genetic, neurological and hormonal factors play an important role in the development of deviant sexuality (Berlin, 1983; Bradford, 1985; Langevin et al., 1985; Rada, Laws \& Kellner, 1976). On the other hand, most psychological theories attribute sexually deviant behavior to a number of intra-psychic and developmental factors. Numerous studies have attempted to explain this phenomenon from psychoanalytic, behavioral, social learning, and cognitive perspectives (Abel, Blanchard \& Jackson, 1974; Gardner, 1950; Glueck, 1952; Malmquist, 1972; Segal \& Stermac, 1990).

Interpersonal theories examine sexual deviance in terms of social encounters of the individual, namely peer interactions, bonding problems (Hirschi, 1969; Marshall \& Eccles, 1993; Money, 1986), and interactions with the victims (Morh, Turner \& Jerry, 1964; Revitch \& Weiss, 1962). For example, some researchers see peer subculture, lack of emotional bonding with age-mates, and high risk victim behavior as significant contributors to the causality of a sexual assault.

The inter-group perspective emphasizes the characteristics of family structure, socialization style (Carnes, 1991; Finkelhor, 1984; Knight et al., 1983), and schooling factors (Ageton, 1983; Awad \& Saunders, 1989; Fehrenback et al., 1986; Lewis et al., 1979) in relation to the development of sexually abnormal behavior. A number of studies suggest that many sex offenders are raised within a general context of abuse and neglect, come from highly dysfunctional families and experience significant problems at school.

Societal paradigm of sexual deviance interprets this phenomenon within the context of such socio-cultural variables as social disorganization, economic inequality, male dominance, youth exposure to violence and pornography, and negative socio-cultural attitudes (Baron, Straus \& Jaffee, 1988; Finkelhor \& Lewis, 1988; Malamuth \& Check, 1981). Each theory offers valuable insights for understanding the causes of sexually offending behavior; however, the main shortcoming of the above listed approaches is their focus on one or two causality aspects to the virtual exclusion of all the others.

The integrated theory interprets sexual deviance as a multi-causal phenomenon and takes into consideration intrapersonal, interpersonal, inter-group and societal factors. This perspective seems to be the most promising for prevention of sexual abuse and treatment of juvenile and adult sex offenders (Marshall \& Barbaree, 1993).

In contrast to the etiological explanations that are based on scientific research, the process of causal attribution is governed by perception mechanisms and does not always follow the logical scientific schemas or sequence as 
may be expected (Kelly, 1967; 1972). A significant number of studies in the field of causal attribution indicate that our perception is subject to different types of bias and that perceivers tend to make "shortcuts" when provided with insufficient information about another's behavior (Fiske \& Taylor, 1984; Jones \& Nisbett, 1971). Furthermore, the perceiver's explanation of another's behavior can be strongly effected by his or her belief system. Weiner (1993) also suggested that it is causal controllability that determines the attribution of responsibility and affects the perceiver's emotional and behavioral reactions towards the subject.

There is very little research in the area of causal attribution of sexual deviance. Most of the studies in the field of cognition in sexual assault focus on cognitive distortions that are held by adult and juvenile child molesters and rapists. In part, this is due to the shortage of psychometrically sound assessment techniques to measure causal attribution of sexually aberrant behavior.

\section{Methodology}

The purpose of the study was to explore how juvenile sex offenders and non-offenders interpret the causes of sexually deviant behavior and whether causal attributions were linked to cognitive distortions. The principal hypothesis was that both populations perceive sexual deviance as a multi-causal phenomenon; however, due to self-serving bias sex offenders were more likely to externalize its determinants as compared to their pro-social age mates. It was also expected for juvenile offenders to include victim behaviors and characteristics in the causality chain of the abuse cycle and assign less responsibility for sexually deviant behavior to the individual rather than external circumstances.

The subjects of the study were 43 juvenile sex offenders 14 to 19 years of age $(\mathrm{M}=16.84$; $\mathrm{SD}=.93)$. The comparison group was comprised of 45 randomly selected pro-social male youngsters of approximately the same age $(\mathrm{M}=17.11 ; \mathrm{SD}=.87)$.

In an attempt to evaluate the perception of the causality of sexual deviance the author of the study developed the Causal Attribution of Sexual Deviance Questionnaire (CASDQ). The CASDQ is based on Hewstone's classification of the etiology of social phenomena into intrapersonal (biological, psychological); interpersonal (social group influence, victim contribution); intergroup (family variables, schooling factors), and societal (socio-cultural influences) categories. Each of the categories is represented in the questionnaire by five consecutive statements related to the causality of sexual deviance. For example, a statement that "sexual attraction to children is genetically inherited" refers to the biological causes of sexually aberrant behavior, whereas "sexually abnormal behavior is the result of trying to compensate for personally experienced sexual abuse" is the representation of a psychological approach. On the other hand, a statement like "sexually aggressive individuals grow up in discordant and dysfunctional families" best represents family related causality, and "sexual violence against females originates in gender inequality and discrimination against women" refers to the societal paradigm. An assertion that "flirting, provocative dress and behavior are characteristic of rape victims" is an example from the victim subscale, and the statement that "if teachers were better trained in human sexuality, juveniles would not be drawn to abnormal sexual behavior" illustrates a construct from a school related domain. It should also be noted that some questionnaire statements are not direct causal attribution assertions and reflect the causality of sexually deviant behavior by inference. There is also one statement in each category related to prevention or treatment issues of sexually abnormal behavior.

Five additional statements were added to the questionnaire to explore if responsibility was interpreted as an internal or external factor of sexually offending behaviors. The above cluster was named as responsibility subscale. For example, statements like "everybody is equally able to control his sexual inclinations if they wish so", or "the individual himself rather than his life circumstances is to blame for sexual perversion" require to ascribe responsibility either to controllable (internal) or uncontrollable (external) circumstances. The participants of the study were asked to rate each statement on a five-point-rating-scale ranging from "strongly agree" to "strongly disagree".

The appropriateness of the CASDQ was based on content related validity, i.e., all statements were taken from different etiological theories of sexual deviance. The questionnaire was reviewed and endorsed by three experts in the field of juvenile sex offender treatment. The reliability (internal consistency) of the CASDQ was established by calculating Cronbach's alpha $(\mathrm{a}=.64)$.

For result interpretation percentages of "strong agreement" and "agreement" with the statements were lumped together in order to contrast the differences between the responses of juvenile sex offenders and non-offenders. All the percentages were rounded to the closest number. It should also be noted that analysis of variance did not yield statistically reliable results partly due to small participant samples. 


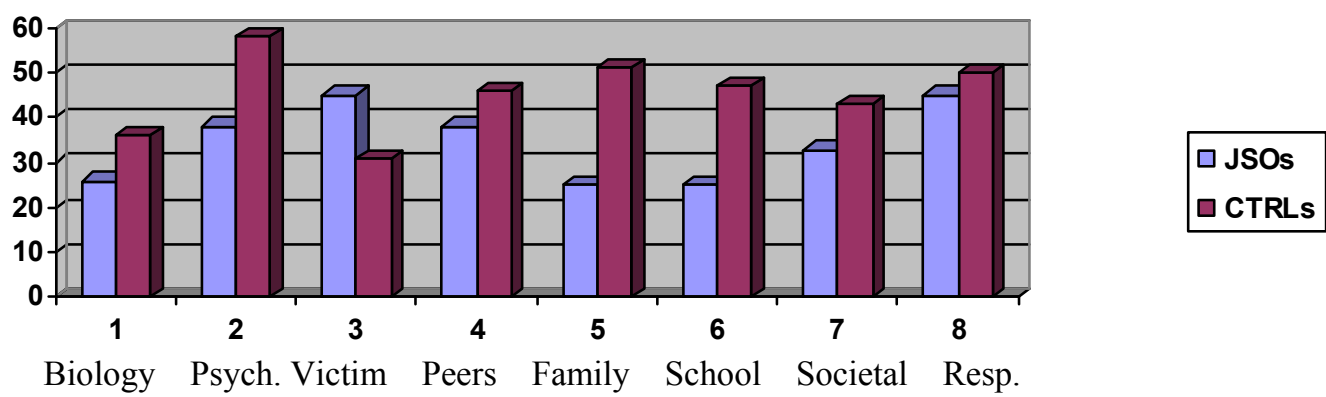

Figure 2. Percentages of high attribution of sexual deviance to different factors

The results in Figure 2 indicate that juvenile sex offenders (JSOs) and adolescents in the control group (CTRLs) interpret sexual deviance as a multicausal phenomenon. However, in the majority of cases prosocial adolescents tend to "strongly agree" or "agree" with statements that attribute sexual deviance to psychological causes (58\%), whereas sexually abusive youth focus on the importance of victims' contribution to the causality of sexually aberrant behavior $(44 \%)$. The percentages are consistent with the averages of juvenile sex offender and non-offender scores on the victim subscale $(\mathrm{M}=3.62, \mathrm{SD}=.82 ; \mathrm{M}=2.76, \mathrm{SD}=.92)$. This finding confirms that sex offenders tend to minimize their responsibility for sexual violence and exaggerate that of their victims. Partial attribution of the causality of sexually deviant behavior to the victim may be a generator of sex offender thinking errors.

Significant differences were noted between the opinion of sexual offenders and non-offenders regarding the role of the family in the causality of the abuse cycle. While $49 \%$ of the subjects in the control group see the family as an important contributor to sexual deviance, only $25 \%$ of juvenile sex offenders acknowledge its significance. The above inconsistency between the two groups may be related to sex offender tendency to minimize the impact of their own microenvironment upon socialization processes.

Since both groups were comprised of older adolescents it is not surprising that juvenile sex offenders and their age mates interpreted peer influence and subculture as significant determinants of sexual deviance. For example, most of the participants from both groups agreed with the statements that "psychological pressure from friends to be as them induces juveniles into early sexual experimentation and domination" and that "sexual violence is directly caused by the subculture of juvenile and youth gangs". On the other hand, such beliefs may serve as justifiers of sexual aggression.

A significant difference was found between the two groups in their perception of the role of the school in the process of socialization. In most cases juvenile sex offenders did not perceive school problems as causal factors of sexual violence $(25 \%)$, whereas pro-social youngsters thought that the relation between the two was much more significant (46\%). Mention should also be made that participants of both groups held the individual to a large degree responsible for sexually deviant behavior (JSOs - 44\%; CTRLs - 49\%); however in some cases the responsibility was externalized by the participants of both groups.

Despite the fact that juvenile sex offenders and non-offenders interpret sexual deviance as a multicausal phenomenon, the study confirms the hypothesis that causal attribution of sexual violence in sex offender population is related to thinking errors and cognitive distortions. In the majority of cases juvenile offenders tend to assign responsibility for their aberrant behavior to victim characteristics and impact of their peers. This is consistent with a number of psychological and sociological findings indicating that the acceptance of negative attitudes towards females or children is related to higher frequencies of rape and child abuse, and that denial of responsibility and guilt enables sex offenders to continue to behave in socially unacceptable ways and avoid efforts leading to change. On the other hand, thinking errors are reinforced by psychological self-serving biases and help sex offenders to deal with painful emotions, shame and anxiety.

\section{Discussion}

Although participants of both groups exhibited a number of cognitive distortions, juvenile sex offenders did it more often as compared to their pro-social age mates. Cognitive distortions or thinking errors serve a number of purposes such as rejecting responsibility, denying victim's suffering, allowing the offending to continue and avoiding painful emotional consequences. Realization of the fact by the offender that he has seriously harmed the victim or the society challenges his perception of himself as of a decent individual. Thinking errors 
characteristic to sex offenders are, in a way, similar to self-serving attributions that enable them to blame external or situational factors rather than personal deficiencies. They arise well before the offence is committed and serve as significant risk factors that tend to increase the likelihood of recidivism.

A single study can hardly determine the exact linkage mechanisms between causal attribution of sexual deviance and cognitive distortions; however it is obvious that the two are related. For this reason it would be beneficial to continue to conduct research in the area of causal attribution of sexual deviance. As far as practical application of the study is concerned, the author recommends that the subject of etiology of sexual abuse be included in sex education programs. Causal attribution of sexual deviance should be also addressed in counseling sessions with juvenile sex offenders.

\section{References}

Abel, G. G., \& Osborn, C. A. (1992). The paraphilias: The extent and nature of sexually deviant and criminal behavior. In J. M. W. Brandford (Ed.), Psychiatric Clinics of North America, 15(3). W. B. Saunders Company, Philadelphia, PA, 675-687.

Abel, G. G., Becker, J. V., \& Mittleman, M. S. (1987). Self-reported sex crimes of non-incarcerated paraphiliacs. Journal of Interpersonal Violence, 2, 3-25. http://dx.doi.org/10.1177/088626087002001001

Abel, G. G., Blanchard, E. B., \& Jackson, M. (1974). The role of fantasy in the treatment of sexual deviation. Archives of General Psychiatry, 30, 467-475. http://dx.doi.org/10.1001/archpsyc.1974.01760100035007

Ageton, S. (1983). Sexual assault among adolescents. Annals, MA: Annals Books.

American Psychiatric Association. (2000). Diagnostic and statistical manual of mental disorders -IV-Text revised. Washington, D.C.

Awad, G. A., \& Saunders, E. (1989). Adolescent child molesters: Clinical observations. Child Psychiatry and Human Development, 19, 195-206.

Baron, L., Straus, M. A., \& Jaffee, D. (1988). Legitimate violence, violent attitudes, and rapes: A test of the cultural spillover theory. In R. H. Prentky, \& V. L. Quinsey (Eds.), Human sexual aggression (pp. 79-111). New York: The New York Academy of Sciences.

Becker, J. V., Cunningham-Rathner, J., \& Kaplan, M. S. (1986). Adolescent sexual offenders: Demographics, criminal and sexual histories and recommendations for reducing future offenses. Special Issue: The prediction and control of violent behavior: II. Journal of Interpersonal Violence, 1, 431-445. http://dx.doi.org/10.1177/088626086001004003

Berlin, F. S. (1983). Sex Offenders: A biomedical perspective and a status report on biomedical treatment. In J. G. Greer, \& I. R. Stuart (Eds.), The sex aggressor: Current perspectives on treatment. New York: Van Nostrand.

Bradford, J. M. W. (1985). Organic treatments for the male sexual offender. Behavioral Science and the Law, 3, 55.

Carnes, P. (1991). Don't call it love. Deerfield Park, FL: Health Communications, Inc.

Fehrenbach, P. A., Smith, W., Monastersky, C., \& Deisher, R. W. (1986). Adolescent sexual offenders: Offender and offense characteristics. American Journal of Orthopsychiatry, 56, 225-233. http://dx.doi.org/10.1111/j.1939-0025.1986.tb02722.x

Finkelhor, D., \& Lewis, I. A. (1988). An epidemiologic approach to the study of child molestation. In R. A. Prentky, \& V. L. Quinsey (Eds.), Human Sexual Aggression (pp. 64-79). New York: The New York Academy of Sciences.

Finkelhor, D. (1984). Child sexual abuse: New theory and research. New York: The Free Press.

Fiske, S. T., \& Taylor, S. E. (1989). Social cognition. Reading, MA: Addison-Wesley.

Gardner, G. G. (1950). The community and the aggressive child. Mental Hygiene, 34, 44-63.

Glueck, B. (1952). Study and treatment of persons convicted of crimes involving sexual aberrations: Final report on research project. Albany: New York State Department of Mental Hygiene.

Hirschi, T. (1969). Causes of delinquency. Berkley, University of California Press.

Jones, E. E., \& Nisbett, R. E. (1971). The actor and the observer: Divergent perceptions of the causes of behavior. Morristown, NJ: General Learning Press. 
Kelley, H. H. (1967). Attribution theory in social psychology. In D. Levine (Ed.), Nebraska symposium on motivation (Vol. 15). Lincoln: University of Nebraska Press.

Kelly, H. H. (1972). Causal schemata and the attribution process. In E. E. Jones, D. E. Kanouse, H. H. Kelley, R. E. Nisbett, S. Valuis, \& B. Weiner (Eds.), Attribution: perceiving the causes of behavior. Morristown, N.J.: General Learning Press.

Knight, R., Prentky, R., Schneider, B., \& Rosenberg, R. (1983). Linear causal modeling of adaptation and criminal history in sex offenders. In K. Van Dusen, \& S. Medinick (Eds.), Prospective studies of crime and delinquency (pp. 303-341). Boston.

Langevin, R, Hucker, S. J., Ben-Aron, M. H., Purin, J. E., \& Hook, H. J. (1985). Why are pedophiles attracted to children? Further studies of erotic preference in heterosexual pedophilia. In R. Langevin (Ed.), Erotic preference, gender identity, and aggression in men: new research studies. Hillsdale, N. J. Erlbaum.

Laws, R. D., \& O’Donohue, W. (1997). Fundamental issues in sexual deviance. In D. R. Laws, \& W. O’Donohue (Eds.), Sexual deviance. Theory, assessment and treatment. (pp. 1-21). New York: The Guilford Press.

Lewis, D. O., Shankok, S. S., \& Pincus, J. H. (1979). Juvenile male sexual assaulters. American Journal of Psychiatry, 136, 1194-1196.

Longo, R. E. (1982). Sexual learning and experience among adolescent sexual offenders. International Journal of Offender Therapy and Comparative Criminology, 26, 235-241. http://dx.doi.org/10.1177/0306624X8202600305

Longo, R. E., \& Groth, A. N. (1983). Juvenile sexual offenders in the histories of adult rapists and child molesters. International Journal of Offender Therapy and Comparative Criminology, 27, 150-155. http://dx.doi.org/10.1177/0306624X8302700207

Malamuth, N. M., \& Check, J. V. P. (1981). The effects of mass media exposure on acceptance of violence against women: A field experiment. Journal of Research in Personality, 15, 436-446. http://dx.doi.org/10.1016/0092-6566(81)90040-4

Malmquist, C. P. (1972). Juvenile sex offenders. In H. L. Resnik, \& M. E. Wolfgang (Eds.), Sexual behaviors: Social, clinical, and legal aspects (pp. 76-77). Boston: Little, Brown.

Marshall, W. L., \& Barbaree, H. E. (1990). An integrated theory of the etiology of sexual offending. In W. L. Marshall, D. R. Laws, \& H. E. Barbaree (Eds.), Handbook of sexual assault: Issues, theories, and treatment of the offender (pp. 257-275). New York: Plenum Press.

Marshall, W. L., \& Eccles, A. (1993). Pavlovian conditioning processes in adolescent sex offenders. In H. E. Barbaree, W. L. Marshall, \& S. M. Hudson (Eds.), The juvenile sex offender (pp. 118-142). New York: Guilford Press.

Mohr, J. W., Turner, R. E., \& Jerry, J. B. (1964). Pedophilia and exhibitionism. A Handbook. Toronto: University of Toronto Press.

Money, J. (1986). Lovemaps: clinical concepts of sexual/erotic health and pathology, paraphilias and gender transposition, childhood, adolescence and maturity. New York: Irving Publishers.

Rada, R. T., Laws, D. R., \& Kellner, R. (1976). Plasma testosterone levels in the rapist. Psychosomatic Medicine, 38, 257.

Revitch, E., \& Weiss, R. G. (1962). The pedophilic offender. Diseases of nervous system, 23, 73-78.

Segal, Z. V., \& Stermac, L. E. (1990). The role of cognition in sexual assault. In W. L. Marshall, D. R. Laws, \& H. E. Barbaree (Eds.), Handbook of sexual assault: Issues, theories, and treatment of the offender (pp. 161-174). New York: Plenum.

Weiner, B. (1993). On sin versus sickness: A theory of perceived responsibility and social motivation. American Psychologist, 48, 957-965. http://dx.doi.org/10.1037/0003-066X.48.9.957 


\section{Causal Attribution of Sexual Deviance Questionnaire}

Inside this booklet you will find a number of statements about human sexual behavior. There are no "right" or "wrong" answers because scientists are still disputing these issues and have not developed a commonly acceptable theory. All you have to do is check the box that seems to best represent your opinion.

Before you start the actual test, please read the example below and think how you would respond to it.

\section{Example:}

Truly religious people will never sexually abuse a child.

\section{Strongly Agree Agree Don't Know Disagree Strongly Disagree}

\section{Please Ask Now If Something Isn'T Clear.}

When you are told to, start with the first statement and continue until you have responded to all of the statements. Keep the following things in mind:

1. Respond only the way you think.

2. You may have as much time as you need, but try to proceed fairly fast. It is best to give the first response that comes to your mind.

3. Respond to every statement. Don't skip any.

\section{Personal Information}

\begin{tabular}{lll}
\hline Name & Age & \\
\hline Gender & Male & Female \\
Your level of education & Grade School High School College \\
Do you have a criminal record? & Yes & No \\
Are you currently employed? & Yes & No \\
\hline
\end{tabular}

Indicate Your Level of Agreement with Each of the Following Statements:

\begin{tabular}{lcrr}
\hline Statements & Strongly & Agree Don't & Disagree Strongly \\
& Agree & Know & Disagree \\
\hline
\end{tabular}

1. Sexually abnormal behavior is related to the lack or excess of corresponding chemicals in the brain.

2. Predisposition to sexual attraction to children is genetically inherited.

3. Sexual aggression is the manifestation of an individual's physiological or somatic disorder.

4. Medical treatment is the most reliable means for overcoming sexually abnormal behavior.

5. Individuals that are inclined to sexual violence differ from others by their appearance.

6. Sexually abnormal behavior is the result of trying to compensate for a personally experienced sexual abuse.

7. Sexually deviant behavior is identical to drug addiction in that one gets addicted to it as one does to an intoxicant.

8. Psychotherapy is the most reliable means to overcome sexual deviancy.

9. Sexual aggression against women is an attempt to prove one's masculinity. 
10. Frequent intimate sexual fantasizing about deviant behavior eventually develops into corresponding sexual inclinations.

11. Flirting, provocative dress and behavior are characteristics of rape victims.

12. If a child voluntarily strips naked in front of an adult, he or she is seeking a more intimate contact with him.

13. Sexual violence against children would end if they would be taught how to behave responsibly.

14. Girls that complain of having been raped during a date are usually trying to protect their reputation.

15. The unrestrained behavior of girls in a party is a manifestation of an unconscious desire to be forced to have sex with someone.

16. Group therapy and discussions are the best means to prevent juvenile sexual offending.

17. The psychological pressure from older friends ,to be as them" induce juveniles into sexual experimentation and violence.

18. A basic assumption for the development of pedophilia is an individual's isolation from peers and the inability to make friends with them.

19. Sexual violence is a by-product of the subculture of juvenile and youth gangs.

20. Children who "play doctors" in peer groups develop deviant inclinations.

21. Educating the family and family therapy are the basic means by which juvenile sexual violence can be prevented.

22. Sexual aggression in children is caused from their being abused or neglected by their family.

23. Sexually aggressive behavior of boys is the result of an unconscious conflict with their fathers or other male care givers.

24. Sexually violent behavior of children is determined by the anti-social values of the family.

25 . Sexually aggressive individuals grow up in dysfunctional and promiscuous families.

26. Juveniles that experience constant failure in school compensate through sexual violence outside of school.

27. Lack of proper supervision of children in a day care center causes the older children to sexually abuse the younger.

28. If teachers provided more information about human sexuality, juveniles would not be interested in abnormal sexual behavior.

29. Children who experience stress in school tend to 
avoid it and become sexually violent.

30. Children who are provided with correct information about family ethics, religious and social norms regarding sexual behavior do not develop deviant inclinations.

31. Pornography and violence as shown in movies and on television directly influence similar behavior in juveniles.

32. Hyper sexuality in youth and their deviant behavior are directly linked to trends of modern life style.

33. Sexual violence against females originates in gender inequality as well as discrimination against women.

34. Sexual perversion is the result of the liberal laws regarding sexual freedom.

35. Raising the subsistence level of at-risk families could eliminate sexual violence in society.

36. The individual himself rather than his/her life's circumstances is to blame for their sexual perversion.

37. Deviant sexual inclinations are not the result of a physical illness but an individual's free choice.

38. If an adult has sexual intercourse with a juvenile, the adult should get the same punishment even if it was the juvenile who initiated sexual interaction.

39. Everyone is equally able to control his/her sexual inclinations if they so wish.

40. Regardless of any mitigating circumstances, recurring sexual abuse is to be punished more severely than the first. 